\section{Negociando saberes e poderes: a Política Nacional de Atenção Integral à Saúde do Homem e a Sociedade Brasileira de Urologia}

\section{Negotiating knowledge and power: the National Policy for Comprehensive Men's Healthcare and the Brazilian Society of Urology}

\section{Rita Flores Müller}

Pesquisadora, Grupo Epos: genealogias, subjetivações e violências/ Instituto de Medicina Social/Universidade do Estado do Rio de Janeiro; Grupo Traumas e Catástrofes/Universidade Federal do Rio de Janeiro (UFRJ), Université Paris Diderot-Paris 7.

Rua do Catete, 30, ap.1001

22220-000 - Rio de Janeiro - RJ - Brasil

ritafloresmuller@gmail.com

\section{Joel Birman}

Psicanalista; professor, Instituto de Psicologia/UFRJ; pesquisador e professor, Laboratório de Psicanálise, Medicina e Sociedade/Université Paris 7.

Avenida Pasteur, 250

22290-240 - Rio de Janeiro - RJ - Brasil

joelbirman@uol.com.br

Recebido para publicação em fevereiro de 2014.

Aprovado para publicação em outubro de 2014.

http://dx.doi.org/10.1590/S0104-59702016005000011
MÜLLER, Rita Flores; BIRMAN, Joel.

Negociando saberes e poderes: a Política Nacional de Atenção Integral à Saúde do Homem e a Sociedade Brasileira de Urologia. História, Ciências, Saúde Manguinhos, Rio de Janeiro, v.23, n.3, jul.-set. 2016, p.703-717.

\section{Resumo}

O objetivo do artigo é evidenciar as negociações e disputas entre saberes e poderes na história da Política Nacional de Atenção Integral à Saúde do Homem, a partir da criação da Área Técnica de Saúde do Homem, instituída em 2008 no Departamento de Ações Programáticas Estratégicas no Ministério da Saúde. Acompanhamos a posição da Sociedade Brasileira de Urologia no processo de constituição da política. Recuperamos a disputa colocada em discurso tendo como referência as entrevistas realizadas com gestores do Ministério da Saúde e com o representante auxiliar do Fundo de População das Nações Unidas no Brasil. Nas aparições do sujeito de direitos à saúde, analisamos a visibilidade do corpo masculino nos signos das resistências às intervenções do biopoder.

Palavras-chave: medicalização; sexualidade masculina; Política Nacional de Atenção Integral à Saúde do Homem; Brasil.

\section{Abstract}

The aim of this article is to demonstrate the negotiations and disputes between different kinds of knowledge and power in the history of the Brazilian National Policy for Comprehensive Men's Healthcare based on the creation in 2008 of the Technical Area for Men's Health within the Ministry of Health's Department of Strategic Programs. We observed the Brazilian Society of Urology's position as the policy was being drawn up, including the discourse adopted, based on interviews held with managers from the Ministry of Health and the assistant representative of the United Nations Population Fund in Brazil. We analyzed the visibility of the male body in signs of resistance to the interventions of biopower in the expression of the right to health.

Keywords: medicalization; male sexuality; National Policy for Comprehensive Men's Healthcare; Brazil. 
$\mathrm{A}$ s novas tecnologias do sexo têm incrementado o vetor "ativo" da masculinidade por meio do dispositivo da sexualidade e da scientia sexualis (Foucault, 1988). Nessa aparelhagem de produção de verdades apoiada em diversas instituições, redes de saber e atores sociais, é a verdade sobre o sexo do homem que vem se destacando na cena contemporânea. Sexualidade, portanto, está na ordem do dia na presente discussão, mas também o corpo da realidade biopolítica e da diferença sexual, uma vez que é submetido às gramáticas normativas de constituição corporal para fins produtivos - produção de modos de prazer, produção de fármacos de consumo, de reprodução social, mas, em última instância, produção de um território corporal masculino que se permita tocar, invadir, examinar, antecipar, explorá-lo em sua funcionalidade; enfim, que se permita íntimo e desnudo.

Na análise da medicalização da sexualidade masculina no tocante à sua regulamentação e normalização, a tessitura dos elementos simbólicos é marcada pela hibridização de seus jogos de verdade, saber e poder (Foucault, 1994), em que o corpo do homem ocupa o lugar de impressão do poder que visibiliza inscrições históricas também descontínuas acerca de seus próprios objetos. No processo de regulação da sexualidade e apreensão quanto ao futuro da população frente às aspirações do Estado, convém rememorar que a criação de uma ciência do homem, e de seu corpo como objeto de intervenção, teve na "luta" contra a sífilis no século XIX, na preocupação com o controle das doenças venéreas, com o alcoolismo e a tuberculose, sua condição de possibilidade, dada a ameaça à ordem social que instauravam (Carrara, 1996). Na problemática proposta, o corpo do homem é o próprio arquivo (Derrida, 2001) como suporte na contemporaneidade que revisita a historicidade dos males da sexualidade masculina delineada pelo combate à sífilis no século XIX. No limite da biopolítica, como administrar um corpo que resiste ao toque da medicalização?

Nosso recorte incide na criação da Área Técnica de Saúde do Homem em 2008 no Departamento de Ações Programáticas Estratégicas (ATSH-Dapes) no Ministério da Saúde (MS). Acompanhamos a posição destacada da Sociedade Brasileira de Urologia (SBU) no processo de constituição da Política Nacional de Atenção Integral à Saúde do Homem no Brasil (PNAISH). Recuperamos a disputa colocada em discurso tendo como referência as entrevistas realizadas com dois gestores do Ministério da Saúde e uma entrevista com o representante auxiliar do Fundo de População das Nações Unidas (UNFPA) no Brasil.

As entrevistas com os gestores federais e com o representante auxiliar do UNFPA no Brasil foi uma das etapas da pesquisa multicêntrica "Homens e serviços de saúde II: rompendo barreiras culturais, institucionais e individuais (Recife/PE, São Paulo/SP e Florianópolis/SC)". O objetivo dessa etapa foi recuperar algumas narrativas de criação da Política. Toda a primeira formação da ATSH foi entrevistada no próprio Ministério da Saúde, embora para a escrita deste artigo tenham sido eleitas as três entrevistas já citadas. A pesquisa foi realizada de acordo com as regulamentações legais do Comitê de Ética em Pesquisa com Seres Humanos e, ao longo do artigo, todos os nomes são fictícios, para preservar o anonimato dos entrevistados.

O primeiro gestor, André (médico obstetra, assessor do ministro da Saúde José Gomes Temporão), participou ativamente do processo de constituição da política, desde a elaboração dos primeiros diagnósticos sociodemográficos e de saúde da população masculina até a formação daquele que viria a ser o grupo pioneiro da referida área no Dapes. O segundo gestor, 
João (psicólogo, consultor convidado para o grupo embrionário da ATSH e, posteriormente, coordenador), compôs o primeiro grupo da ATSH.

No momento em que as negociações são postas em relevo na relação entre governo, especialidades médicas e sociedade civil organizada, quem seria eleito para exercer o aparato do cuidado da sexualidade masculina e, nessa negociação, como alinhavar interesses tão diversos?

\section{A composição da Área Técnica de Saúde do Homem no Ministério da Saúde}

No "recontar" do processo de elaboração da política de saúde para a população masculina, foi na recorrência das tensões entre os saberes e poderes que se visibilizou uma rede de lugares distintos, na qual o "sujeito da política" se dispersou e se produziu (Foucault, 2009). À medida que as posições institucionais definiam seus regimes de verdade e "travavam suas disputas", a tensão inerente a esse jogo de forças ofereceu-se como objeto de análise e condição de possibilidade das reflexões tecidas neste artigo.

Nessa dança das cadeiras, estamos nos referindo às vozes dos diferentes atores representados pelos urologistas da SBU - institucionalmente destacada como o "mais saber" em relação às demais instituições e especialistas das sociedades médicas ${ }^{1}$ - e pelos pesquisadores das universidades brasileiras e militantes de movimentos sociais no campo das masculinidades e do feminismo - com destaque para algumas organizações não governamentais da sociedade civil identificadas nas entrevistas com os gestores de saúde. ${ }^{2}$

A necessidade de uma política que se constituísse no diálogo da sociedade civil com as sociedades médicas foi uma orientação do então ministro da Saúde José Gomes Temporão, ao apresentar como uma das prioridades de sua gestão a criação de uma "Saúde do homem". De acordo com o gestor André, "o ministro deixou muito claro que queria que a construção da Política fosse um processo articulado e que envolvesse a sociedade civil, mas que envolvesse também as sociedades médicas".

Elaborado na "parceria entre gestores do SUS [Sistema Único de Saúde], sociedades científicas, sociedade civil organizada, pesquisadores, acadêmicos e agências de cooperação internacional" (Brasil, 2009b, p.7), o documento sistematizador reúne os princípios e as diretrizes que serão materializadas no Plano de Ação Nacional 2009-2011 (Brasil, 2009a) da política em questão. Na leitura do documento Princípios e diretrizes (Brasil, 2009b), é possível perceber a incorporação das diferentes instâncias da sociedade que participaram das etapas de construção dessa política, conforme nomeadas na própria apresentação da publicação federal. Segundo este documento, a política foi elaborada por meio de:

um minucioso processo de análises e discussões com o Conass [Conselho Nacional de Secretários de Saúde], o Conasems [Conselho Nacional de Secretarias Municipais de Saúde], a universidade, as organizações profissionais como as de cardiologia, urologia, gastroenterologia, psiquiatria, pneumologia, medicina da saúde da família e comunidade, as entidades da sociedade civil organizada para as questões de gênero e outros grupos populacionais (Brasil, 2009b, p.9).

Ainda no tocante à elaboração da PNAISH, nas palavras de Sérgio Carrara, Jane Russo e Livi Faro (2009, p.661; destaque nosso), a formulação da política retrata "uma curiosa articulação entre especialistas médicos..., gestores e formuladores de políticas públicas e representantes 
dos 'movimentos organizados', produzindo, em linguagem muitas vezes híbrida, uma proposta capaz de dar conta de interesses bastante diversos".

O entrevistado André (gestor 1, MS) recupera a contratação de João (gestor 2, MS) como o primeiro consultor para o planejamento da ATSH. A ênfase foi dada à visão madura desse profissional, advinda de seu trabalho com grupos de homens e da elaboração dos levantamentos bibliográficos nacionais e latino-americanos das instituições que desenvolviam trabalhos com a população masculina.

A busca de um coordenador que "tivesse alguma visão de sexualidade" pautou-se como critério de escolha para a coordenação da área. Nesse momento, André era o coordenador do Departamento de Ações Programáticas Estratégicas do Ministério da Saúde (Dapes/MS), e João, o consultor da embrionária Área Técnica.

Entrevistado: Eu já era diretor do Dapes há algum tempo, nós passamos ao desafio de montar uma Área Técnica, ver quais os consultores que moravam em Brasília e que poderiam ser um núcleo desta Área Técnica, e conseguir também um coordenador, alguém que tivesse alguma visão de sexualidade, eu também já tinha feito curso de especialização em sexologia, então já tinha esta visão mais geral (André, gestor 1, MS).

Entre a "sexualidade" e a "sexologia" entra em cena Ricardo Cavalcanti, um dos fundadores da moderna sexologia brasileira da linhagem de Masters e Johnson, como o gestor com o trânsito entre as "entidades médicas" e o "conhecimento da sexualidade", conforme o trecho a seguir:

Entrevistado: A Área Técnica da Saúde do Homem ficou dentro do Dapes e precisou buscar um coordenador que tivesse trânsito com as entidades médicas mas que ao mesmo tempo conhecesse sexualidade. Depois de muito esforço de ligar para vários lugares..., encontramos o professor Ricardo Cavalcanti (André, gestor 1, MS).

Cabe ressaltar que Ricardo Cavalcanti não foi entrevistado, e, dada sua importância no processo de constituição da política, recorremos ao mapeamento realizado na pesquisa Sexualidade, ciência e profissão no Brasil (Russo et al., 2011). Nessa publicação, há caminhos de análise para posicionar discursivamente o gestor em relação à sexologia e à urologia, mas, principalmente, em relação às tensões percebidas nos regimes enunciativos, datadas na formação do primeiro grupo de técnicos da ATSH no Ministério da Saúde.

Entrevistado: O professor Ricardo Cavalcante, que é sexólogo, formação de base ginecologia e obstetra, mas há 30 anos não exercia mais a função, um homem já de 70 anos que era uma referência da sexologia, presidente da Associação Mundial de Sexologia e presidente da comissão de sexologia da Associação de Ginecologia e Obstetrícia, da comissão de sexologia da Associação Latino-americana de Sexologia, um homem que tinha dois cursos regulares no Brasil, mais de oito livros publicados na temática de sexologia (André, gestor $1, \mathrm{MS}$ ).

Segundo Carrara, Russo e Faro (2009), a importância da sexualidade na construção da nova política espelhou-se no fato de que a coordenação da ATSH, criada em março daquele ano, seria dada inicialmente ao gestor Ricardo Cavalcanti. Confundem-se, nesse processo, "sexologia" e "sexualidade" como saberes que dariam conta de abarcar a amplitude do campo de atuação que se propõe uma política de saúde do homem no Brasil. 
Nesse sentido, é interessante a maneira como um dos gestores explicita a importância desse saber híbrido para homens não fixados em uma subjetividade restrita à normativa heterossexual. O "discurso da diversidade" aciona diferentes sujeitos da política, ao fragmentar a suposta identidade que persiste sob as prerrogativas do direito sexual e reprodutivo, na definição do "par heterossexual" da estratégia biopolítica em favor de uma abordagem do "todo mundo", não menos exposta, diga-se de passagem, às práticas de regulamentação e governamentalidade. Segundo o gestor: "Quem trata sexologia não trata mulher, trata homem, trata casal, trata pessoas quer sejam lésbicas, bissexuais, travestis, transgêneros, enfim, trata todo mundo" (André, gestor 1, MS).

Nesse caso, a afirmação dos direitos sexuais passa pela sexologia e pela medicina sexual (Carrara, Russo, Faro, 2009, p.673). Autores demarcam que o final do século XIX até o final dos anos 1920 é um intervalo de efervescência da emergência de um discurso sobre sexo no Brasil (Russo et al., 2011). A sexologia brasileira do início do século XX sofreu influências exercidas pela sexologia internacional ligada aos "desvios sexuais", ou "patologias sexuais", no que os autores denominam a primeira sexologia (Béjin, 1987). ${ }^{3}$ Como já afirmado, Ricardo Cavalcanti representou historicamente o campo da sexologia na PNAISH, sobretudo no diálogo com a SBU e na participação desta no processo de constituição da política e dos contornos que seriam impressos nos saberes sobre a sexualidade masculina. Carrara, Russo e Faro (2009, p.663) recuperam a pressão exercida pela SBU:

Desde pelo menos 2004, a SBU vinha se dedicando à causa da saúde do homem, e, ao longo de todo o ano de 2008, passa a exercer forte pressão junto a diferentes setores do governo, a parlamentares, aos conselhos de saúde (Conass e Conasems) e a outras sociedades médicas, para o lançamento de uma política específica voltada à saúde do homem. Em sua atuação, além do estabelecimento das diretrizes dessa política, estavam em jogo questões coorporativas, como o valor dos honorários pagos ao urologista pelo SUS ou a obrigatoriedade de os urologistas vinculados ao SUS serem credenciados pela sociedade.

No entanto, essa não foi a única pressão exercida junto à constituição de uma política de atenção integral à saúde do homem no Brasil. O gestor João da ATSH abordou os diferentes enfoques a partir do que ele denominou "resistências" no compartilhamento de supostos saberes a respeito da "saúde do homem". A sociedade civil organizada, os movimentos sociais e as organizações de especialidades médicas brasileiras (em especial a SBU) travaram suas disputas. A construção de uma política pública, entendida como um conjunto de ações coletivas direcionadas à garantia dos direitos sociais, traduz-se numa construção que se dá justamente no interior da complexa teia social (Arretche, 2003). Coexistem territórios de disputa de poder que ganham corpo e materialidade tanto por intermédio de instituições objetivas na operacionalização da relação Estado/sociedade quanto a partir das relações subjetivas que são caracterizadas e perpassadas pelas instâncias socioculturais.

Essa disputa posta em discurso evidenciou-se segundo a inteligibilidade inerente a suas lutas, estratégias e táticas (Foucault, 1982), pois é justamente aí que a análise desses enunciados ganha força - na versão da história que se conta ao ser contada. É a política do corpo do homem que a política de saúde visibiliza, por meio de sua aparelhagem do Estado, seus objetivos gerais e específicos, princípios e diretrizes, seu plano de ação. 
De um lado, uma política de atenção integral à saúde do homem pautada pela atenção básica à saúde, de outro, uma política de saúde do homem pautada pelas especialidades médicas. Em linhas gerais, a arena em que se assistiram aos embates ideológicos e políticos cindiu-se nessa representação. Na composição desse cenário, podemos propor uma relação de correspondência entre os gestores que se destacaram de um lado e de outro. Se Ricardo Cavalcanti esteve para uma política das especialidades - sendo a SBU sua maior porta-voz na consolidação da urologia como a ciência do homem -, o entrevistado André, da assessoria do MS, esteve para uma política de atenção integral - sendo ele o próprio expoente na representação pela atenção básica à saúde.

Ao reiterar a política de atenção à saúde do homem como uma intervenção em saúde que tem "implicações de gênero", o representante do UNFPA avaliou as iniciativas de trabalho com homens na cena brasileira:

Entrevistado: A América Latina tem bons exemplos nos países; inclusive agora o Brasil criou há um ano uma política de saúde do homem, que é bom dizer que é uma política no campo da saúde, ela se pretende uma política para promover o acesso dos homens a serviços de saúde, que tem implicações de gênero, mas ela é uma política no domínio da saúde (Silvio, UNFPA).

É importante destacar que o "discurso de gênero", ou "enfoque de gênero", é constituinte do documento Princípios e diretrizes da PNAISH em sua totalidade (Brasil, 2009b). Uma análise da bibliografia desse documento indica a presença de universidades e pesquisadores brasileiros que têm se dedicado aos estudos das masculinidades e sua estreita relação com a saúde. Encontram-se não apenas, mas principalmente, pesquisas que subsidiaram a construção da política, no formato de diagnósticos sociais acerca de serviços voltados à população masculina. Além disso, a base teórica da matriz de gênero que fundamenta esse documento tem no livro de Judith Butler (2003), Problemas de gênero, sua força conceitual, ainda que esse discurso adquira um caráter instrumental, híbrido ou até mesmo "postiço" em determinados momentos. Além da filósofa estadunidense, estão presentes na bibliografia os autores Michel Bozon (2002) e Daniel Welzer-Lang (2001).

Aqui o sistema de dispersão dos enunciados está regulado pela insistência do gênero que se fabrica como aquele dispositivo crítico da masculinidade hegemônica e de significados culturais de saúde/doença. Isso se traduz em diferentes linguagens ao longo dos documentos Princípios e diretrizes (Brasil, 2009b) e Plano de Ação Nacional (Brasil, 2009a), mas que indicam pistas de como esse se faz presente. No primeiro documento, em uma rápida incursão encontramos referências como "estereótipos de gênero" (Brasil, 2009b, p.14), "heterogeneidade das possibilidades de ser homem" (p.15) e "promoção da equidade" (p.17). E, finalmente, como um dos objetivos específicos da política, a saber, "incluir o enfoque de gênero, orientação sexual, identidade de gênero e condição étnico-racial nas ações educativas" (p.55).

Foi sob esse pano de fundo que o gestor André (gestor 1, MS) fez uma ressalva, delimitando os territórios constituintes da relação entre sociedades médicas e a sociedade civil/universidades brasileiras na marca dos saberes sobre o corpo do homem e de sua política de saúde. Se no início do texto foi registrada a orientação do ministro da Saúde José Gomes Temporão sobre a necessidade do diálogo com as especialidades médicas na construção da referida política, 
aqui a chegada de Ricardo Cavalcanti atende justamente à necessidade de reconhecimento da existência de um campo estabelecido, com o qual esse gestor - então "facilitador" dos diálogos com as disciplinas médicas - teria também que dialogar, negociar e transitar.

Entrevistado: Então quando a área vai se montando e quando o Ricardo Cavalcanti chega, ele já encontra uma visão, ele já encontra um trabalho, uma concepção de que tudo bem entidades médicas, mas tem muita gente na academia e outros grupos que já trabalham há muito tempo com a questão da saúde do homem (André, gestor 1, MS).

No duelo de forças entre os dois campos, é oportuno recuperar a noção do corpo do homem como o "lugar de impressão" (Derrida, 2001, p.8) do poder que visibiliza inscrições históricas também descontínuas acerca de seus próprios objetos. Foi na interseção das estratégias dos poderes/saberes em questão que esse corpo movimentou as contraposições históricas dos interesses defendidos pelos diversos setores instituconas.

A questão tem seu cerne na medicalização do corpo masculino, obturado pelas disputas que indicam direções de ação divergentes. Nesse caso, ao repetir uma história já contada, produz-se a diferença do que se espera para uma política de saúde do homem e, principalmente, o que se deseja não repetir: a redução do corpo masculino à próstata como se reduziu, no passado, o corpo da mulher ao útero. É um enunciado-mestre, pois carrega o teor de acontecimento da política analisada. Ao mesmo tempo, faz do passado seu presente constitutivo - a condição de possibilidade de uma temporalidade "didática" que somente se conjuga "hoje" ao lançarse para o ontem e para o amanhã.

Entrevistado: Se a gente for ver o homem como no passado se via a mulher, igual a útero, mulher igual à mama, então não preciso de uma política de atenção integral. É preciso fazer algo completamente diferente, completamente inovador, algo transversalizado, algo que perpasse por todas as especialidades e que tenha uma visão muito clara da atenção básica, que foi outra polêmica que tivemos inclusive internamente, ou seja, estamos construindo uma política para especialistas para fortalecer sempre as especialidades ou estamos construindo uma política que tenha como carro-chefe a prevenção e a promoção da saúde? Se estamos construindo uma política que tem como carro-chefe a promoção e a prevenção da saúde, a base desta política é a atenção primária, é a atenção básica, que é a porta de entrada do SUS (André, gestor 1, MS).

Reside aqui a importância do que será abordado mais detidamente adiante, catalisado pela ameaça silenciosa da próstata que encontrou no significante "útero" sua condição analítica, muito além do que o câncer como o "mal" propriamente dito repete como o "mesmo" das estratégias de promoção e prevenção de saúde.

No desejo de imprimir sua visão à construção da política, o entrevistado também marcou uma posição institucional a favor de uma política das não especialidades médicas. Vislumbramos, portanto, o movimento descontínuo dos tempos passado, presente e futuro, todos inscritos e inscrevendo-se no projeto desejado para o corpo do masculino. O corpo feminino aparece e desaparece - se dá a ver como inscrito naquilo que já foi, mas abre a reflexão sobre o corpo do homem e a lança a partir daquele, para escrevê-lo novo e oposto ao seu apagamento. Daí a importância de citá-lo novamente como o modelo do não (Derrida, 1991), pois é em sua negatividade produtiva que se pode afirmar a importância de não reduzir o corpo do homem ao seu elemento naturalizante, pautado pela fragmentação corporal (útero, 
mamas, próstata, pênis), e não pela sua integralidade em saúde. Decorre daí a força enunciativa do gestor ao afirmar que "nós não podemos permitir que a elaboração da política seja feita por urologistas, ou seja, até porque urologista não é médico só de homem" (André, gestor 1, MS).

Nas entrevistas com os gestores, foi a "urologia da SBU" como uma ciência do homem que se destacou. Essa afirmação corrobora a feita por Carrara, Russo e Faro (2009, p.663) de que "embora a urologia não seja uma especialidade voltada apenas para o homem, a própria SBU tende a apresentá-la como tal, tão grande é o peso das questões de saúde masculina em sua pauta". ${ }^{4}$ Atualmente a andrologia se constitui parte da urologia e é, nesse âmbito, definida como uma subespecialidade urológica que trata "do sistema reprodutor, da função sexual e da regulação de hormônios masculinos” (SBU, s.d.).

A discussão sobre impotência sexual, a transformação da impotência em disfunção erétil e a atuação da SBU foram peças fundamentais na construção da nova política de atenção à saúde do homem (Carrara, Russo, Faro, 2009). Nesse rol há que se incluir a "popularização" da vasectomia, tornada acessível no SUS como uma das estratégias de aproximação dos homens dos serviços de saúde, e que encontra sua potência de interesse sob a rubrica da saúde sexual e reprodutiva e do planejamento familiar (Müller, 2012).

Nesse contexto, a relação de hibridização entre natureza-cultura-tecnologia (Haraway, 1995) emerge como condição de possibilidade de uma nova etapa dessa medicalização da vida, em que a valorização das especialidades médicas e o lobby das indústrias farmacêuticas para uma ciência do homem ganham posição preponderante com a tecnologia de uma saúde sexual (Malcher, 2007). Segundo Rohden (2009), até recentemente as mulheres eram o foco recorrente nos discursos sobre esse corpo hormonal, tanto no âmbito científico quanto na divulgação mais ampla. Fenômenos como a tensão pré-menstrual ou as transformações percebidas com a menopausa têm sido chaves explicativas para as mais variadas formas de comportamento e têm também alimentado uma grande indústria de tratamento dos "problemas femininos". A novidade agora é que, com o discurso da Deficiência Androgênica do Envelhecimento Masculino, os homens passam a ser alvos desse tipo de investimento que privilegia a associação entre hormônios, juventude, sexualidade e saúde. Novamente a matriz de impressão e inteligibilidade feminina irrompe a análise aqui tecida, imprimindo sobre outras bases os ditames normativos e medicalizantes, deslocando-se de um corpo a outro, do corpo feminino ao corpo masculino.

Dois elementos precisam ser destacados. Por um lado, a necessária reestruturação dos serviços de saúde enfatizada no plano operativo (Brasil, 2009a) e, nas entrevistas com os gestores, inclusas no investimento na capacitação dos profissionais de saúde para o atendimento da população masculina. No entanto, nos discursos reunidos da SBU, o profissional da urologia vai sendo constituído como porta de entrada dos homens para seu trânsito e encaminhamento aos profissionais das demais especialidades médicas. Segundo Fabíola Rohden (2012, p.2650), em Capturados pelo sexo: a medicalização da sexualidade masculina em dois momentos, via medicalização da sexualidade masculina "com foco na disfunção erétil e a criação de uma nova farmacologia do sexo", arquiteta-se um projeto de captura de homens que exigirá a presença representativa e constante dos urologistas nos serviços de saúde. O fluxo proposto pela SBU contraria, em certo sentido, o sugerido pela própria PNAISH, que tem na atenção básica sua porta de entrada para o atendimento dos 
homens nos serviços públicos. Soma-se a disponibilização de medicamentos no SUS para o tratamento das chamadas disfunções sexuais "para melhorar a qualidade de vida do paciente" (SBU, s.d.) como eixo preponderante da força-tarefa de medicalização da população masculina, verificada na pressão exercida pela SBU a respeito também do valor dos honorários pagos ao urologista pelo SUS, da obrigatoriedade de os urologistas vinculados ao SUS serem credenciados pela SBU e da distribuição gratuita aos pacientes de medicamentos para disfunção erétil e para hiperplasia prostática. ${ }^{5}$

\section{O paciente urológico da Sociedade Brasileira de Urologia}

O ano de 2009 está sendo um marco na aproximação da SBU com os órgãos governamentais. A entidade fez parte das discussões da Política Nacional da Saúde do Homem e assinou um termo técnico de cooperação com o Ministério da Saúde, no qual auxiliará no treinamento dos médicos dos postos públicos, em campanhas educativas, entre outros.

(SBU, s.d.)

Na leitura acerca da produção do sujeito político de direitos à saúde que se objetiva na análise aqui proposta, figura o paciente-urológico da SBU. Essa nomeação adquiriu seu sentido a partir das visitas ao website da SBU (s.d.) e pelas linhas do discurso dos gestores entrevistados, na tentativa de recuperar a participação dessa instituição ao longo do planejamento da referida política. O embate pela legitimidade dos saberes foi impresso no desenho metodológico da política, produzindo-se diferentes verdades na constituição do objeto disputado e de acordo com as estratégias de poder adotadas.

$\mathrm{O}$ acesso ao website da SBU é oferecido de três maneiras. Primeira, restrita a profissionais de medicina cadastrados no Conselho Federal de Medicina; segunda, a associados da SBU e terceira, ao público em geral. Nesta última, notícias são disponibilizadas em forma de releases na opção "Sala de imprensa". Na busca, a primeira notícia disponibilizada que se refere à "Política Nacional de Saúde do Homem", ao "Programa" ou ao "Setor de Saúde do Homem" é datada de 24 de janeiro de 2008. Intitulada "Ministério da Saúde realiza este ano semana de saúde do homem" (Ministério da Saúde..., 24 jan. 2008), o texto recupera o investimento da SBU na criação do setor específico para a população no MS. Na notícia, elencam-se Baldur Schubert como assessor da coordenação do Setor de Saúde do Homem, Ricardo Cavalcanti como coordenador do Setor de Saúde do Homem do MS e, por fim, José Gomes Temporão como Ministro da Saúde:

Desde 2005 a SBU vem lutando para a criação do Setor de Saúde do Homem dentro do Ministério da Saúde, para promover um programa específico voltado às doenças do homem, incluindo ações preventivas e educativas, disse o presidente da SBU. No encontro de hoje, os especialistas discutiram a vasectomia como forma de planejamento familiar, o transplante renal e as doenças da próstata. Mostramos nosso integral apoio para auxiliar as ações que incentivem a formação de equipes de transplantadores, estimulando o aumento de transplantes renais no país. Também vamos sensibilizar nossos associados sobre a importância da vasectomia, afirmou Almeida (Ministério da Saúde..., 24 jan. 2008). 
Na continuidade da busca por informações relativas à participação da SBU na história da política, a segunda notícia publicada no website da instituição é de 27 de maio de 2008. Com o título "Urologistas se reúnem com Ministério da Saúde nesta sexta", a informação refere-se ao encontro da SBU com a ATSH que visou "delinear a Política Nacional de Saúde do Homem que será lançada em agosto pelo ministro da Saúde, José Gomes Temporão" (Urologistas se reúnem..., 27 maio 2008).

A Sociedade Brasileira de Urologia se reúne nesta sexta-feira e sábado, dias 9 e 10, com a Área Técnica de Saúde do Homem do Ministério da Saúde, em Brasília, para debater assuntos do setor urológico que merecem fazer parte da Política Nacional de Saúde do Homem a ser lançada em agosto pelo ministro, José Gomes Temporão. No encontro estarão presentes urologistas de todo o país e representantes do Conselho Nacional de Secretários de Saúde e do Conselho Nacional de Secretários Municipais de Saúde (Urologistas se reúnem..., 27 maio 2008).

No trecho a seguir, e aproveitando o "gancho" do que foi apresentado acima, podemos perceber quais temas do "setor urológico" ganham destaque com a participação dos atores da SBU. A cirurgia voluntária de esterilização masculina (vasectomia) como a forma de inclusão dos homens nas ações de planejamento familiar, assim como as questões de "sexualidade", "tumores urológicos" e aproximação de homens dos serviços de saúde representaram os quatro eixos dos grupos de trabalho definidos para o encontro.

De acordo com o presidente da SBU na ocasião, José Carlos de Almeida, os médicos se dividirão em quatro grupos de estudos sobre: planejamento familiar (vasectomia); sexualidade; tumores urológicos (câncer de próstata, câncer de pênis e hiperplasia benigna da próstata); e fatores que possam aproximar os homens dos serviços de saúde. Após a discussão detalhada de cada área, os assuntos serão levados à plenária para aprovação e redação de um documento com a síntese das sugestões e ações. "Este encontro será de suma importância para ajudarmos o Ministério na construção de uma política inédita sobre a saúde do homem. Temos lutado pela criação desta pasta e desta política há vários anos" - afirma Almeida (Urologistas se reúnem..., 27 maio 2008).

Em 9 de julho de 2008, a notícia "SBU assina convênio com Ministério da Saúde" apresentou o Termo de Cooperação Técnica firmado entre o MS e a SBU. De acordo com o texto, o "objetivo do termo de cooperação técnica é melhorar o atendimento dos homens no SUS e diminuir os índices de mortalidade masculinos" (SBU assina convênio..., 9 jul. 2008). No trecho a seguir, a primeira "novidade" a ser destacada é o direcionamento da atenção aos homens atendidos pelo SUS. A questão é: a que homens a SBU se refere? Entre os objetivos firmados, identifica-se a capacitação dos médicos do SUS para o diagnóstico de doenças urológicas e o auxílio na promoção de campanhas dirigidas ao público masculino com foco na prevenção de doenças.

Os homens atendidos pelo SUS ganharão mais atenção este ano. A Sociedade Brasileira de Urologia acaba de firmar um convênio inédito com o Ministério da Saúde para ajudar a melhorar o atendimento no SUS e o esclarecimento da população masculina. No termo de cooperação técnica, assinado este mês, a entidade médica se compromete em auxiliar na capacitação dos médicos do SUS para diagnóstico de doenças urológicas. Também ajudará na elaboração de campanhas educativas voltadas para a prevenção de 
doenças. A SBU ainda vai elaborar normas e protocolos técnico-científicos sobre doenças urológicas para ampla utilização dos profissionais do SUS, assim, como vai indicar as prioridades em pesquisas urológicas (SBU assina convênio..., 9 jul. 2008).

Além desse convênio, a SBU realizou reuniões com as Áreas Técnicas de Assistência ao Idoso e ao Adolescente do MS para firmar programas de cooperação, "visto que há diversos problemas urológicos que atingem este público, tais como incontinência urinária, disfunção erétil, ejaculação precoce, fimose etc.", declarou José Carlos de Almeida. Em suas palavras: "Vamos trabalhar em conjunto. Queremos aumentar os índices de diagnósticos precoces de doenças masculinas, como o câncer de próstata, que hoje é o segundo câncer que mais mata o homem. Só perde para o câncer de pulmão" (SBU assina convênio..., 9 jul. 2008).

Em 5 de fevereiro de 2009, anuncia-se que o "Ministério da Saúde se reunirá com a SBU periodicamente" (Ministério da Saúde se reunirá..., 5 fev. 2009). Em reunião no dia 4 de fevereiro, urologistas apresentaram a situação do paciente urológico no SUS, e o órgão se propôs a estudar ponto a ponto com a criação de grupos de trabalho. Em 18 de agosto do mesmo ano, a notícia "Urologistas voltam à Câmara dos Deputados" esclarece que "médicos, deputados federais, representantes do Ministério da Saúde e da SBU discutiram políticas de saúde para melhorar o atendimento ao homem no Sistema Único de Saúde" (Urologistas voltam..., 18 ago. 2009). Esse foi o tema do Quinto Fórum de Políticas Públicas e Saúde do Homem que aconteceu na Câmara dos Deputados, em Brasília. O evento anual foi organizado pela Comissão de Seguridade Social e Família a pedido da SBU. Em notícia publicada no site da Câmara dos Deputados em 20 de agosto de 2009, leu-se: "Urologistas pedem mais atenção à saúde do homem" (Urologistas pedem..., 20 ago. 2009).

No projeto de inclusão da população masculina na esfera de cuidados preventivos com a saúde, definia-se entre as entidades médicas o rol de prioridades no desenho da política: o impacto socioeconômico dos "agravos" de saúde dos homens, o paciente masculino uro-oncológico, o câncer de próstata e, por fim, a vasectomia como signo masculino do planejamento familiar.

\section{A próstata, o toque e o útero}

Em uma iniciativa da SBU, a Campanha Nacional de Combate ao Câncer da Próstata em 2011 foi protagonizada pelo ator Tony Ramos, sob a sugestiva chamada: "Exame de próstata: é preciso tocar nesse assunto". Segundo câncer mais comum entre os homens, ficando atrás somente do câncer de pele, uma das três metas estipuladas no Plano de Ação Nacional (2009a) para o período de 2009 a 2011 da política foi o investimento financeiro e de aumento do diagnóstico precoce para esse câncer.

A primeira polêmica se refere à definição de qual deve ser o público-alvo do diagnóstico precoce para o câncer de próstata. O Instituto Nacional de Câncer procura regular a detecção precoce ao recomendar a realização de sensibilização de homens com idade entre 50 e 70 anos que procuram os serviços de saúde por motivos outros que não o câncer da próstata. A SBU, por sua vez, recomenda que os homens acima de 50 anos e os de 40 anos com histórico familiar de câncer de próstata cogitem a possibilidade de ir anualmente ao urologista para fazer check-up da próstata, mesmo que não tenha sintomas urinários. 
Segundo Gomes et al. (2008), numa posição diferente desse consenso, o MS tem insistido na necessidade de todos os homens brasileiros (entre 45 e 75 anos) realizarem os exames de prevenção e diagnóstico precoce de câncer de próstata, seja com urologistas do SUS ou nos demais órgãos públicos federais, estaduais e municipais.

Abandonadas as polêmicas, nosso acento é a caracterização do corpo masculino que adquire uma nova territorialização a partir da identificação da próstata como "peça" corporal eminentemente masculina, numa analogia à posição a que o útero foi alçado na cartografia sintomática corporal entre homens e mulheres. O câncer da próstata é uma doença do homem que acompanha a consideração do câncer como "doença terrível" dos séculos XIX e XX. A indefinição sobre suas causas e seu implacável desenvolvimento criou uma aura de terror em torno da enfermidade. Se o câncer é a "doença terrível", entre os homens o câncer da próstata é o mais terrível de todos (Patterson, 1987) - é o câncer do homem (Coutinho, Soares, 2000).

O que está em jogo é a conexão simbólica, política e econômica entre envelhecimento (ou seu prolongamento com "qualidade de vida" e materializado pelo conceito de "envelhecimento ativo" do MS) e o incremento das performances sexuais masculinas, no tocante às disfunções sexuais, seja no diagnóstico precoce ou seu tratamento. Não é apenas a genitalização do corpo que ganha relevo na análise aqui empreendida, especialmente relativa ao câncer de pênis ou às disfunções sexuais masculinas, mas determinadas "partes" do corpo do homem que precisam ser tocadas, literalmente, como no caso da próstata e sua "ameaça silenciosa" em referência a textos disponíveis no site da SBU de autoria do urologista Ricardo Rocha.

Nas questões pontuadas, a prevenção do câncer de próstata tem uma posição interessante no recontar da história, numa espécie de ponto de estofo em relação ao que se desejou para a política de saúde voltada à população masculina. Especificamente no que se refere à constituição desta, a próstata e sua iminência cancerosa representam a ameaça de o projeto de uma atenção integral à saúde da população masculina se ver reduzido à prevenção e ao tratamento do câncer de próstata.

Recuperamos também a afirmação do representante do UNFPA no Brasil, no momento da entrevista em que avalia as propostas estratégicas da PNAISH e dos desafios de fazê-la chegar aos municípios brasileiros.

Entrevistado: Com 5.573 municípios, como você vai fazer que exista atenção à saúde do homem no país inteiro? Isso é muito difícil. Então começar a apoiar alguns serviços de referência pelo menos para que eles não vejam o 'homem apenas como próstata', porque sempre a saúde do homem, historicamente, era restringida a um ou dois problemas, ou hipertensão ou próstata, e percebam o homem como sujeito de direitos mesmo (Silvio, UNFPA; destaque nosso).

Dito de outra forma, a próstata e os ânimos que ela mobiliza como peça simbólico-corporal eminentemente masculina não dizem respeito apenas à necessidade de monitoramento, prevenção e tratamento dessa glândula de dimensão diminuta localizada na base da bexiga. Nas palavras do gestor André, o exame de toque retal é um exame relativamente simples, "mas historicamente o machismo arraigado, denso, ele não permite. É um tanto quanto agressivo na cabeça absoluta dos homens, se submeter ao exame de toque retal". O toque retal é uma medida preventiva de baixo custo financeiro, porém de custo simbólico alto, o que implica o afastamento de inúmeros homens da prevenção do câncer de próstata. Nesse sentido, não 
se trata apenas de um exame físico que possa diagnosticar precocemente tal câncer, já que não toca apenas na próstata. Ele toca em aspectos simbólicos da subjetividade masculina que, se não trabalhados, podem não só inviabilizar essa medida de prevenção secundária como também a atenção à saúde do homem em geral. Mais do que na próstata propriamente dita, pesquisas brasileiras com homens acerca do assunto convergem na conclusão empírica de que o toque retal toca na masculinidade (Souza, Silva, Pinheiro, 2011).

A resistência do corpo-homem à medicalização clivou-se no que reduz o homem à próstata para encontrar na redução da mulher ao útero a possibilidade de uma repetição diferencial (Deleuze, 2006). O par "próstata/útero" impõe o reconhecimento de sua posição no arquivo justamente porque se arquiva ao conservar a potência do mal que enuncia - momento esse em que próstata e útero se unem sob os olhares do biopoder.

$\mathrm{O}$ arquivo compreende tanto a memória como seu desfalecimento: o arquivo existe quando conjugado a uma consignação exterior que lhe é própria, assegurando a possibilidade da repetição, reprodução ou da reimpressão (Derrida, 2001). ${ }^{6}$

Simultânea e paradoxalmente, o arquivo constituído para a escrita deste artigo e de seu recorte analítico se apresenta instituindo algo novo e conservando o que ali estava. $\mathrm{O}$ ato enunciativo que reduz o homem à próstata visibiliza no arquivo a abertura à potência dispersiva dessa redução. Ao se destacar como ameaça silenciosa, enuncia em alto e bom som as lembranças de uma disputa travada outrora sob o corpo feminino igualmente reduzido ao útero. Lembranças não saudosistas, porque incômodas, mas que exigem ser conservadas como condição de possibilidade de tocar, aqui sim, um homem-sujeito de direitos à saúde que esfacela o que a ameaça prostática mantém arquivado.

\section{Considerações finais}

Como analisar o campo de constituição de uma política de saúde para a população masculina que propõe justamente "tocar os homens" nos signos das resistências ao projeto de medicalização do social? Como aproximá-los dos serviços de saúde, no sentido de inserilos nos regimes da atenção integral, de prevenção e promoção da estilística de uma vida "saudável"? Ou, ainda, recuperando o questionamento de um dos gestores entrevistados, por que os homens não se cuidam como nós desejamos? Como discurso normalizador estatal do biopoder, a política propõe responder a essa questão oferecendo-se como veículo da própria mudança cultural que reivindica.

Critério de norteamento das correlações de poder e saber, o corpo masculino é revisitado em sua medicalização contemporânea, na submissão aos processos de positivação de suas energias constitutivas, visando-se extrair dele uma série de vantagens políticas e econômicas, advindas de sua função produtiva e multiplicadora do poder intensamente reconhecida e implementada.

Analisar as irrupções do homem-sujeito de direitos à saúde é percebê-lo também sendo lançado ao "mesmo" que se repete pelas ameaças que ainda mantém arquivada sua posição de exterioridade dos serviços públicos de saúde. 


\section{NOTAS}

${ }^{1}$ Ao contrário do que aconteceu com a busca por informações da SBU, para as demais sociedades/especialidades médicas, o resultado foi escasso. Um resumo de artigo foi encontrado na base de dados BVSPsi, "Saúde cardiovascular do homem brasileiro: visão da Sociedade Brasileira de Cardiologia", a respeito da participação dessa sociedade ao longo dos encontros com o Ministério da Saúde. Ver Chagas et al. (2009).

${ }^{2}$ Foram elas: Instituto Promundo (RJ), Instituto Papai (PE), Instituto Noos (RJ).

${ }^{3}$ Ver Rohden (2009).

${ }^{4}$ Carrara, Russo e Faro (2009) tecem referência à constituição da andrologia no Brasil em torno da década de 1930, a partir do trabalho de José de Albuquerque. Durante os anos 1930-1940, este que se proclamava criador da andrologia tinha justamente os urologistas entre seus principais alvos, merecendo críticas contundentes do sexólogo por quererem monopolizar o estudo e a intervenção sobre os problemas sexuais masculinos. Para Albuquerque, ao lado da ginecologia, a andrologia devia ser considerada subespecialidade da sexologia (Carrara, Russo, Faro, 2009, p.663).

${ }^{5}$ Problema urinário comum que afeta os homens ou "aumento prostático benigno" (HPB). A glândula prostática que circunda a uretra começa a crescer, comprimindo-a. A causa exata da HPB não é conhecida, mas os pesquisadores acreditam que ela se dá, em parte, por alterações hormonais no decorrer do processo de envelhecimento.

${ }^{6}$ A análise parte da citação de Freud em O mal-estar na cultura, em que Derrida (2001, p.22-23) identifica uma pulsão de morte: uma pulsão silenciosa, que destrói o arquivo e, por isso, é arquiviolítica. O mal de arquivo é, então, o princípio que permite o arquivo e que o condiciona à destruição.

\section{REFERÊNCIAS}

ARRETCHE, Marta.

Dossiê agenda de pesquisas em políticas públicas. Revista Brasileira de Ciências Sociais, v.18, n.51, p.7-9. 2003.

BÉJIN, André.

O poder dos sexólogos e a democracia sexual. In: Ariès, Phillipe; Béjin, André (Org.). Sexualidades ocidentais: contribuições para a história e para a sociologia da sexualidade. São Paulo: Brasiliense. p.236-254. 1987.

BOZON, Michel.

Sociologie de la sexualité. Paris: Nathan. 2002.

BRASIL.

Ministério da Saúde. Secretaria de Atenção à Saúde. Departamento de Ações Programáticas Estratégicas. Plano de Ação Nacional 2009-2011 da Política Nacional de Atenção Integral à Saúde do Homem. Brasília: Ministério da Saúde. Disponível em: http://www.unfpa.org.br/Arquivos/plano_ nacional.pdf. Acesso em: 10 jan. 2016. 2009a.

BRASIL.

Ministério da Saúde. Secretaria de Atenção à Saúde. Departamento de Ações Programáticas Estratégicas. Política Nacional de Atenção Integral à Saúde do Homem: princípios e diretrizes. Brasília: Ministério da Saúde. Disponível em: http://www. unfpa.org.br/Arquivos/saude_do_homem.pdf. Acesso em: 10 jan. 2016. 2009b.

BUTLER, Judith.

Problemas de gênero: feminismo e subversão da identidade. Rio de Janeiro: Civilização Brasileira. 2003.

CARRARA, Sérgio.

Tributo a Vênus: a luta contra a sífilis no Brasil, da passagem do século aos anos 40. Rio de Janeiro: Editora Fiocruz. 1996.

CARRARA, Sérgio; RUSSO, Jane; FARO, Livi. A política de atenção à saúde do homem no Brasil: os paradoxos da medicalização do corpo masculino. Physis: Revista de Saúde Coletiva, v.19, n.3, p.659-678. 2009.

CHAGAS, Antonio Carlos Palandri et al.

Saúde cardiovascular do homem brasileiro: visão da Sociedade Brasileira de Cardiologia. Arquivos Brasileiros de Cardiologia, v.93, n.6, p.584-587. Disponível em: http://www.scielo.br/scielo. php?script=sci_arttext\&pid=S0066-782X200900 $1200004 \& \operatorname{lng}=\mathrm{pt} \& \mathrm{nrm}=\mathrm{iso} \& \operatorname{lng}=\mathrm{pt}$. Acesso em: 10 jan. 2016. 2009.

COUTINHO, Marília; SOARES, Gláucio. Homens: a maioria desorganizada. Dados, v.43, n.2. Disponível em: http://www.scielo.br/scielo. php?pid=S0011-52582000000200004\&script=sci arttext. Acesso em: 10 jan. 2016. 2000.

DELEUZE, Gilles.

Diferença e repetição. Rio de Janeiro: Graal. 2006.

DERRIDA, Jacques.

Mal de arquivo: uma impressão freudiana. Rio de Janeiro: Relume Dumará. 2001. 
DERRIDA, Jacques.

Limited Inc. Campinas: Papirus. 1991.

FOUCAULT, Michel.

A arqueologia do saber. Rio de Janeiro: Forense Universitária. 2009.

FOUCAULT, Michel.

Les technologies de soi-même. In: Foucault, Michel. Dits et écrits, v.4. Paris: Gallimard. p.520-545. 1994.

FOUCAULT, Michel.

A história da sexualidade: a vontade de saber. Rio de Janeiro: Graal. 1988.

FOUCAULT, Michel.

Microfísica do poder. Rio de Janeiro: Graal. 1982.

GOMES, Romeu et al.

A prevenção do câncer de próstata: uma revisão da literatura. Ciência e saúde coletiva, v.13, n.1, p.235-246. Disponível em: http://www.scielo. br/scielo.php?script=sci_arttext\&pid=S1413$81232008000100027 \& \ln g=$ pt\&nrm=iso\&tlng=pt. Acesso em: 10 jan. 2016. 2008.

HARAWAY, Donna.

Saberes localizados: a questão da ciência para o feminismo e o privilégio da perspectiva parcial. Cadernos Pagu, v.5, p.7-41. 1995.

MALCHER, Leonardo Fabiano Souza.

Aos cuidados de Príapo: impotência sexual masculina, medicalização e tecnologia do corpo na medicina do Brasil. Tese (Doutorado em Antropologia Social) - Instituto de Filosofia e Ciências Humanas, Universidade Federal do Rio Grande do Sul, Porto Alegre. 2007.

MINISTÉRIO DA SAÚDE...

Ministério da Saúde realiza este ano semana de saúde do homem. SBU, 24 jan. 2008.

Disponível em: www.sbu.org.br. Acesso em: 10 jun. 2012. 24 jan. 2008.

MINISTÉRIO DA SAÚDE SE REUNIRÁ...

Ministério da Saúde se reunirá com a SBU periodicamente. SBU, 5 fev. 2009. Disponível em: www.sbu.org.br. Acesso em: 14 jun. 2012. 5 fev. 2009.

MÜLLER, Rita de C.F.

A constituição de uma política de saúde para homens no Brasil: bases simbólicas e lugares de enunciação (2009-2011). Tese (Doutorado em Teoria Psicanalítica) - Centro de Filosofia e Ciências Humanas, Instituto de Psicologia, Universidade Federal do Rio de Janeiro. 2012.

PATTERSON, James.

The dread disease: cancer and modern American culture. London: Harvard University Press. p.839-878. 1987.
ROHDEN, Fabíola.

Capturados pelo sexo: a medicalização da sexualidade masculina em dois momentos. Ciência e Saúde Coletiva, v.17, n.10, p.2645-2654. 2012.

ROHDEN, Fabíola.

Diferenças de gênero e medicalização da sexualidade na criação do diagnóstico das disfunções sexuais. Revista Estudos Feministas, v.17, n.1, p.89-109. Disponível em: https:// periodicos.ufsc.br/index.php/ref/article/view/ S0104-026X2009000100006. Acesso em: 10 jan. 2016. 2009.

RUSSO, Jane et al.

Sexualidade, ciência e profissão no Brasil. Rio de Janeiro: Centro Latino-americano em Sexualidade e Direitos Humanos. Disponível em: http://www.clam.org.br/uploads/conteudo/ sexualidade_ciencia_profissao.pdf. Acesso em: 13 jul. 2012. 2011.

SOUZA, Luccas M. de; SILVA, Michelli P.; PINHEIRO, Ingrid $\mathrm{S}$.

Um toque na masculinidade: a prevenção do câncer de próstata em gaúchos tradicionalistas. Revista Gaúcha de Enfermagem, v.32, n.1, p.151-158. 2011.

SBU.

Sociedade Brasileira de Urologia. Disponível em: http://www.sbu.org.br/. Acesso em: 10 jan. 2016. s.d.

SBU ASSINA CONVÊNIO...

SBU assina convênio com Ministério da Saúde. SBU, 9 jul. 2008. Disponível em: www.sbu.org.br. Acesso em: 20 jun. 2012.9 jul. 2008.

\section{UROLOGISTAS PEDEM...}

Urologistas pedem mais atenção à saúde do homem. Câmara dos Deputados, 20 ago. 2009. Disponível em: www.sbu.org.br. Acesso em: 20 jun. 2012. 20 ago. 2009.

UROLOGISTAS SE REÚNEM...

Urologistas se reúnem com Ministério da Saúde nesta sexta. SBU, 27 maio 2008. Disponível em: www.sbu.org.br. Acesso em: 26 jun. 2012. 27 maio 2008.

UROLOGISTAS VOLTAM...

Urologistas voltam à Câmara dos Deputados. SBU, 18 ago. 2009. Disponível em: www.sbu.org. br. Acesso em: 26 jun. 2012. 18 ago. 2009.

WELZER-LANG, Daniel.

A construção do masculino: dominação das mulheres e homofobia. Revista Estudos Feministas, v.9, n.2, p.460-482. 2001. 